\title{
Article \\ High Current Field Emission from Large-Area Indium Doped ZnO Nanowire Field Emitter Arrays for Flat-Panel X-ray Source Application
}

\author{
Yangyang Zhao, Yicong Chen, Guofu Zhang, Runze Zhan, Juncong She, Shaozhi Deng (i) and Jun Chen * (D) \\ Key Laboratory of Optoelectronic Materials and Technologies, Guangdong Province Key Laboratory of Display \\ Material and Technology, School of Electronics and Information Technology, Sun Yat-Sen University, \\ Guangzhou 510275, China; zhaoyy53@mail2.sysu.edu.cn (Y.Z.); chenyc25@mail.sysu.edu.cn (Y.C.); \\ zgfbb@126.com (G.Z.); zhanrz3@mail.sysu.edu.cn (R.Z.); shejc@mail.sysu.edu.cn (J.S.); \\ stsdsz@mail.sysu.edu.cn (S.D.) \\ * Correspondence: stscjun@mail.sysu.edu.cn
}

Citation: Zhao, Y.; Chen, Y.; Zhang, G.; Zhan, R.; She, J.; Deng, S.; Chen, J. High Current Field Emission from Large-Area Indium Doped $\mathrm{ZnO}$ Nanowire Field Emitter Arrays for Flat-Panel X-ray Source Application. Nanomaterials 2021, 11, 240. https:// doi.org/10.3390/nano11010240

Received: 17 December 2020

Accepted: 15 January 2021

Published: 18 January 2021

Publisher's Note: MDPI stays neutral with regard to jurisdictional claims in published maps and institutional affiliations.

Copyright: (c) 2021 by the authors. Licensee MDPI, Basel, Switzerland. This article is an open access article distributed under the terms and conditions of the Creative Commons Attribution (CC BY) license (https:/ / creativecommons.org/licenses/by/ $4.0 /)$.

\begin{abstract}
Large-area zinc oxide $(\mathrm{ZnO})$ nanowire arrays have important applications in flat-panel $X$-ray sources and detectors. Doping is an effective way to enhance the emission current by changing the nanowire conductivity and the lattice structure. In this paper, large-area indium-doped $\mathrm{ZnO}$ nanowire arrays were prepared on indium-tin-oxide-coated glass substrates by the thermal oxidation method. Doping with indium concentrations up to 1 at $\%$ was achieved by directly oxidizing the In-Zn alloy thin film. The growth process was subsequently explained using a self-catalytic vaporliquid-solid growth mechanism. The field emission measurements show that a high emission current of $20 \mathrm{~mA}$ could be obtained from large-area In-doped sample with a $4.8 \times 4.8 \mathrm{~cm}^{2}$ area. This high emission current was attributed to the high crystallinity and conductivity change induced by the indium dopants. Furthermore, the application of these In-doped $\mathrm{ZnO}$ nanowire arrays in a flat-panel $X$-ray source was realized and distinct $X$-ray imaging was demonstrated.
\end{abstract}

Keywords: Indium doped $\mathrm{ZnO}$ nanowire; thermal oxidation; field emission; flat-panel X-ray source

\section{Introduction}

Larger area one-dimensional (1D) cold cathode arrays play an important role in panel light sources, flat-panel X-ray sources, and photodetectors [1-4]. In these materials, field emission properties from zinc oxide $(\mathrm{ZnO})$ nanowire has been extensively studied in recent years [5-11], demonstrating facile synthesis of uniform large-area samples that possess low turn-on fields, good emission stabilities, and uniform emission site [12,13]. Therefore, largearea $\mathrm{ZnO}$ nanowire field emission arrays (FEAs) have been studied and their subsequent application in various vacuum microelectronic devices has been demonstrated. Chen et al. have reported a larger-area flat-panel $\mathrm{X}$-ray source comprising a $\mathrm{ZnO}$ nanowire field emitter that produced a uniform distribution of X-ray generation owing to the uniform electron emission [2]. Furthermore, a double-sided radiating large-area flat-panel X-ray source device has been reported that produced clear X-ray images with high contrast [14]. Zhang et al. have prepared a flat-panel photodetector using $\mathrm{ZnO}$ nanowire FEAs exhibiting an excellent light response performance in a wide spectral range [15].

For these applications, a high emission current is essential to obtain a high-performance device. For example, a high emission current would make possible a high-brightness flatpanel X-ray source and thus a short exposure would be adequate for imaging. Whereby, high-speed X-ray imaging of moving objects could be realized without blurring. Previous studies have explored various approaches to enhance the $\mathrm{ZnO}$ nanowires emission current, including changing the morphology to increase the field enhancement factor, reducing the screening effect by optimizing the population density, lowering the work function by post-treatment, and improving the electrical property by lowering the back contact or via 
nanowire element doping [7,16-19]. Among these methods, element doping is an effective way to enhance the emission current by changing the nanowire conductivity and the lattice structure $[20,21]$. Zinc oxide is a typical n-type doped semiconductor owing to the intrinsic oxygen vacancies, and n-type doping is typically preferred to reduce the resistivity of $\mathrm{ZnO}$ nanowires. In previous studies, the most commonly used metal element dopants are $\mathrm{Al}$, $\mathrm{Ga}$, In, and Ge [20-27].

Various attempts to prepare doped $\mathrm{ZnO}$ nanowires have be made including both hydrothermal growth [21,28] and thermal evaporation [23,24]. Lv et al. have synthesized Al-doped $\mathrm{ZnO}$ nanowires by a facile hydrothermal method under a $100{ }^{\circ} \mathrm{C}$ solution [21]. Ahmad et al. used thermal evaporation to prepare In-doped $\mathrm{ZnO}$ nanowires at $700{ }^{\circ} \mathrm{C}$ and 133.32 Pa pressure, in which the $\mathrm{Zn}, \mathrm{ZnO}$ and indium powders was mixture as the ingredient [24]. In addition, the growth of $\mathrm{ZnO}$ nanowires with $\mathrm{Cu}, \mathrm{Ga}$, and Sb elements doping has been reported using the thermal evaporation method with typical growth temperatures over $700{ }^{\circ} \mathrm{C}$ [29-31]. Most studies using thermal evaporation have required a high temperature to achieve high-quality nanowire growth, which precludes the use of the glass substrates essential for large-area sample preparation.

Previous researches have shown that the influence of element doping on the electrical and field emission performance of $\mathrm{ZnO}$ is significant. Nunes et al. have reported the effects on the electrical properties of $\mathrm{ZnO}$ films with the $\mathrm{Al}, \mathrm{Ga}$, and In element doping, reporting a lowest resistivity of $\mathrm{ZnO}$ film with $1 \mathrm{at} \%$ of indium doping [32]. Zhou et al. have synthesized $\mathrm{ZnO}$ nanowires with Ga doping using chemical vapor deposition method, where the nanowire resistivity decreased by two orders of magnitude $\left(10^{-1}\right.$ to $\left.10^{-3} \Omega \cdot \mathrm{cm}\right)$ after doping [25]. In addition to these elements, researchers have also studied the effects that doping $\mathrm{ZnO}$ nanowires with other elements on its electrical properties. Improved $\mathrm{ZnO}$ nanowire electrical properties were observed with F-doping by post-processing [33]. Ahmad et al. have synthesized $\mathrm{ZnO}$ nanowires with In doping that exhibited a superior field emission performance [24]. These previous results demonstrated that element doping can effectively improve the electrical properties of $\mathrm{ZnO}$ nanowires and thereby enhance their field emission properties.

Thermal oxidation is a feasible method to prepare $\mathrm{ZnO}$ nanowire FEAs on largearea glass substrates owing to its low temperature growth [6]. Furthermore, because the $\mathrm{ZnO}$ nanowires are directly grown from $\mathrm{Zn}$ films, the nanowires can be easily patterned by a microfabrication process thereby easily achieving integration of nanowires in gated FEAs [15,34-37]. Tuning the nanowire field emission properties has been attempted using element doping. For example, element doping via plasma post-treatments in a $\mathrm{NH}_{3}$ plasma or via low-energy ion implantation with fluorine doping has been reported [33,38]. However, direct element doping in $\mathrm{ZnO}$ nanowires during the thermal oxidation preparation process has not yet been realized, primarily owing to the relatively low growth temperature. However, the melting point of indium matches the thermal oxidation growth temperature, and thus it is feasible to grow In-doped $\mathrm{ZnO}$ nanowires directly with indium as a doping element using thermal oxidation. However, the attempt has not yet been reported.

In this study, we synthesized large-area In-doped $\mathrm{ZnO}$ nanowire arrays on an indiumtin-oxide (ITO)-coated glass substrate by the thermal oxidation method. The structure and optical properties of the nanowires were characterized, and a self-catalytic thermal oxidation growth method was proposed to explain the growth of the $\mathrm{ZnO}$ nanowire with indium doping. The field emission properties and maximum current of the prepared In-doped nanowires were measured, confirming the excellent performance of the samples. Furthermore, a flat-panel $\mathrm{X}$-ray source was fabricated using the $\mathrm{ZnO}$ nanowire array with indium doping as the cathode, which achieved uniform emission and clear X-ray imaging of biological and non-biological samples. These results are of great significance to the application of large area indium doped $\mathrm{ZnO}$ nanowires in vacuum electronic devices. 


\section{Experimental}

$\mathrm{ZnO}$ nanowires with indium doping were prepared via thermal oxidation of an In- $\mathrm{Zn}$ alloy thin film. Arrays of round patterns were prepared on glass substrates, where each round pattern had a $5 \mu \mathrm{m}$ diameter and $1600 \times 1600$ patterns existed on a $4.8 \times 4.8 \mathrm{~cm}^{2}$ area with a $25 \mu \mathrm{m}$ spacing between adjacent patterns. The pattern diameter and spacing were chosen to minimize the screening effect, according to a previous work [19]. To observe the cross-sectional morphology of the nanowires, the $\mathrm{ZnO}$ nanowires were also prepared on silicon substrates.

The sample preparation process started with depositing an ITO film $520 \mathrm{~nm}$ thick on a glass substrate, where the ITO film acted as the electrode layer. Patterns of photoresist were formed on the ITO electrode layer by ultraviolet (UV) lithography. Bombarded with Ar ions for $30 \mathrm{~min}$ prior to deposition of the indium-zinc (In-Zn) alloy film on the pattern via electron beam evaporation. The evaporation source was the In-Zn alloy particles comprised 20\% In and 80\% Zn (Aoshi Science and Technology Co. Ltd., Shenyang, China). The In-Zn alloy film thickness was about $2 \mu \mathrm{m}$. whose pattern was formed using a lift-off method. Finally, the sample was grown by thermal oxidation in which placed in a threetemperature zone tubular furnace. During growth, the temperature was increased from room temperature to $470{ }^{\circ} \mathrm{C}$ in $192 \mathrm{~min}$, and maintained at this temperature for $3 \mathrm{~h}$ in ambient atmosphere, and then cooled to room temperature naturally. Through this process, indium doped zinc oxide nanowires arrays were obtained.

The morphology and structure of the prepared In-doped $\mathrm{ZnO}$ nanowires were characterized by scanning electron microscopy (SEM; SUPRA ${ }^{\mathrm{TM}} 60$, Zeiss, Oberkochen, Germany). The crystalline structure was examined by X-ray diffractometry (XRD; D/Max-IIIA, Rigaku Corporation, Tokyo, Japan) using $\mathrm{Cu} \mathrm{K} \alpha$ radiation (1.54056 ̊ wavelength) and by highresolution transmission electron microscopy (HRTEM; Titan G2 300 KV, FEI, Columbus, NJ, USA). Also, energy-dispersive X-ray spectroscopy (EDX) in the HRTEM instrument was used to verify to the In doping and to visualize the distribution of the In atoms via element mapping. Further determination of the chemical composition was accomplished with X-ray photoelectron spectroscopy (XPS; ESCALAB 250 system, ThermoFisher, Waltham, MA, USA) using Al K $\alpha$ X-rays $(1486.6 \mathrm{eV}, 150 \mathrm{~W})$, in which the energy scale of the spectrometer was calibrated with the $\mathrm{C} 1 \mathrm{~s}$ peak $(284.8 \mathrm{eV})$. Ultraviolet photoelectron spectroscopy (UPS; ESCALAB 250 system, ThermoFisher, MA, USA) was used to measure the sample work function. In addition, Raman spectra were obtained by Raman spectroscopy (FLSP920, Edinburgh Instruments, UK.) with a $523 \mathrm{~nm}$ wavelength Ar ion laser source. Photoluminescence (PL) of single In-doped $\mathrm{ZnO}$ nanowires was measured using the Raman spectroscope (FLSP920, Edinburgh Instruments, UK) with a $325 \mathrm{~nm}$ wavelength UV light from a He-Cd laser at room temperature. The sample was prepared by dripping dispersed nanowire solution on a clean silicon wafer prepared by scraping nanowires off the substrate and ultrasonically dispersing them in alcohol.

The field emission properties were measured in a vacuum chamber with a base pressure of $2.0 \times 10^{-5} \mathrm{~Pa}$. The current-voltage $(\mathrm{I}-\mathrm{V})$ characteristics were measured using a diode structure from which, after going through an aging process, the field emission current versus applied voltage properties were recorded. To observe the emission uniformity, a phosphor screen was used as the anode upon which the field emission image was recorded using a digital camera. The gap between the phosphor screen and cathode was $0.25 \mathrm{~mm}$. To measure the maximum field emission current, a quartz glass substrate coated with an ITO layer was used as the anode, where the gap between the anode and cathode was $0.12 \mathrm{~mm}$.

A diode-structure flat-panel X-ray source was fabricated with the In-doped $\mathrm{ZnO}$ nanowire array as the cathode and a $1 \mu \mathrm{m}$ thick molybdenum thin film on silica glass as the anode. The gap between the cathode and anode was $6 \mathrm{~mm}$, and the device was placed in a vacuum chamber measuring $1.0 \times 10^{-6} \mathrm{~Pa}$. The energy spectra of the $\mathrm{X}$-rays generated by the planar source were recorded by an X-ray detector (X-123SDD, AMPTEK, Inc, Bedford, MA, USA), while an X-ray dosimeter (Magic Max, IBA, Göttingen, Germany) 
was employed to measure the radiation dose. Contact $\mathrm{X}$-ray images were captured by a dental digital imaging detector (RSV4, Visiodent, Clichy, French) for small objects and a flat-panel imaging detector (Xineos-1515, Thousand Oaks, CA, USA) for large objects.

\section{Results and Discussion}

\subsection{Morphology and Structure Characterization}

Figure 1a shows a photograph of the In-doped $\mathrm{ZnO}$ nanowire FEAs prepared on ITO/glass substrate. A low-resolution SEM image featuring a smaller $4 \times 3$ section of the pattern array is shown in Figure $1 b$, while Figure $1 c_{1}, c_{2}$ exhibit typical high-resolution SEM images of a single pattern in the region of $\left(a_{1}\right),\left(a_{2}\right)$ shown in Figure 1a. Figure 1d shows the typical cross-sectional SEM image of a single pattern. From the figure, we can see the In-doped $\mathrm{ZnO}$ nanowire have a tapered morphology near the bottom and a nanowire morphology at the top. Furthermore, we statistically summarize the lengths and diameters of about 100 nanowires distributed across different patterns. The distribution is shown in Figure 1e,f. From the figure, we can see that most nanowires have lengths between $3.5 \mu \mathrm{m}$ and $4 \mu \mathrm{m}$ and diameter of about $70 \mathrm{~nm}$. These results show that a uniform growth of nanowires was obtained on the substrate. The nanowire population density is estimated to be about $9 \times 10^{8} \mathrm{~cm}^{-2}$ by a statistical analysis.
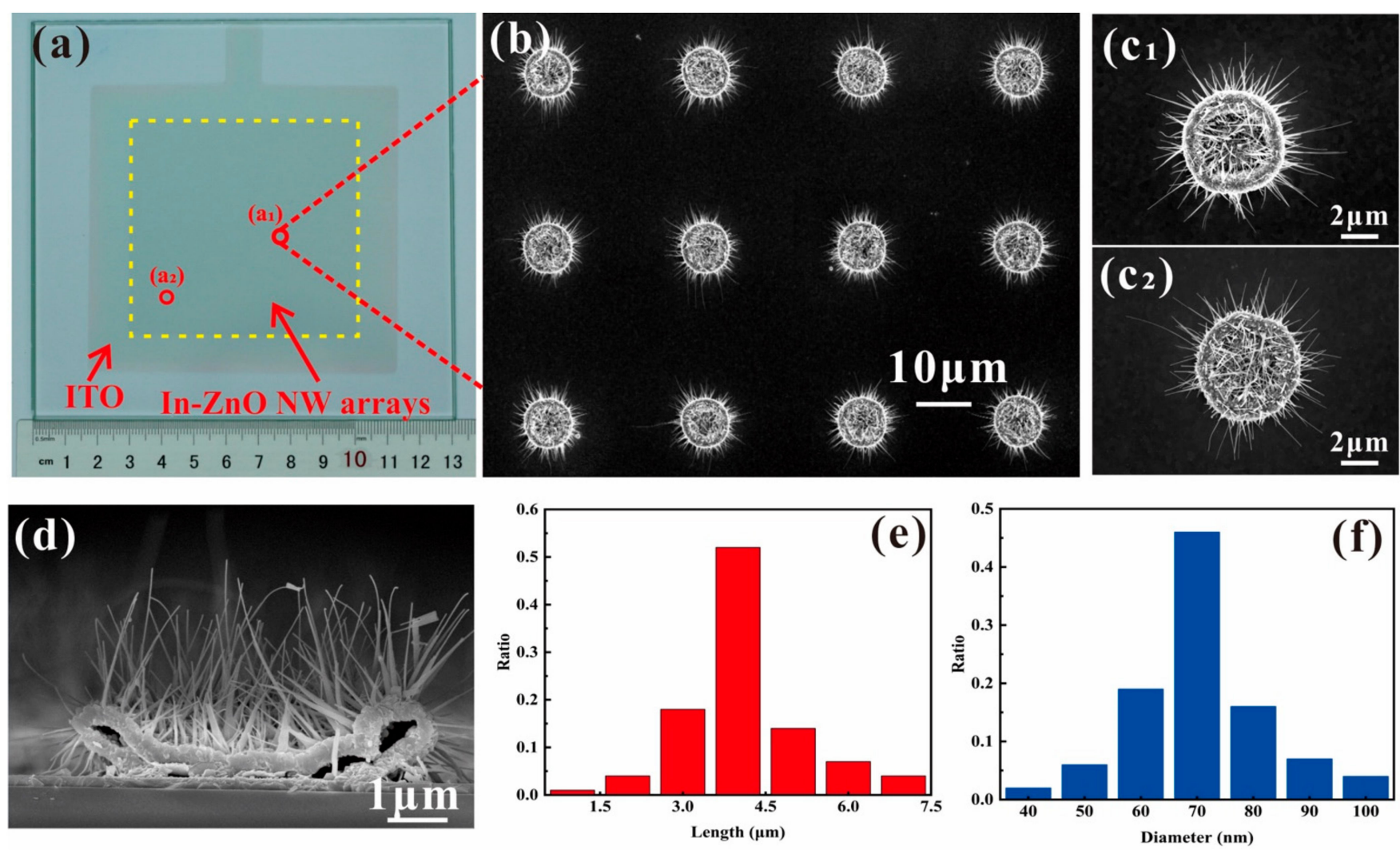

Figure 1. Images of $\mathrm{ZnO}$ nanowire arrays with indium doping. (a) Photograph consist of glass substrate, indium-tin-oxide (ITO) electrode and the prepared $\mathrm{ZnO}$ nanowire field emission arrays (FEAs) with indium doping; (b) top view SEM image of a $4 \times 3$ In-doped $\mathrm{ZnO}$ nanowire pattern array in low magnification; $\left(\mathbf{c}_{\mathbf{1}}, \mathbf{c}_{\mathbf{2}}\right)$ single pattern at different regions in high magnification; and (d) cross-sectional SEM image of a single pattern; (e,f) Statistical results of the length and diameter.

Figure 2a shows a TEM image of a single typical nanowire and its corresponding EDX spectrum (inset in Figure 2a). The EDX spectrum exhibits an obvious indium peak demonstrating an approximate In dopant concentration of $1 \mathrm{at} \%$, proving the presence of indium in the nanowires. Furthermore, a statistical analysis of doping concentration in five individual nanowires shows the doping concentration only has a small fluctuation and 
the average concentration is around $1 \%$. Figure $2 \mathrm{~b}$ shows a HRTEM characterization of the single nanowire in Figure $2 \mathrm{a}$ and the corresponding selected-area electron diffraction (SAED) pattern (obtained from marked region in Figure 2a). The lattice fringe spacing between adjacent lattice planes in Figure $2 \mathrm{~b}$ is measured as $0.29 \mathrm{~nm}$ and the SAED pattern indicates that the nanowire has good crystal quality (inset in Figure 2b). The EDX elemental mapping results for the $\mathrm{Zn}, \mathrm{O}$, and In elements are shown in Figure $2 \mathrm{c}_{1}-\mathrm{c}_{3}$, respectively, in which $\mathrm{Zn}$ and $\mathrm{O}$ exhibit a uniform distribution while In shows a random distribution in the nanowires. This result indicates that the In element was successfully doped into the nanowire.

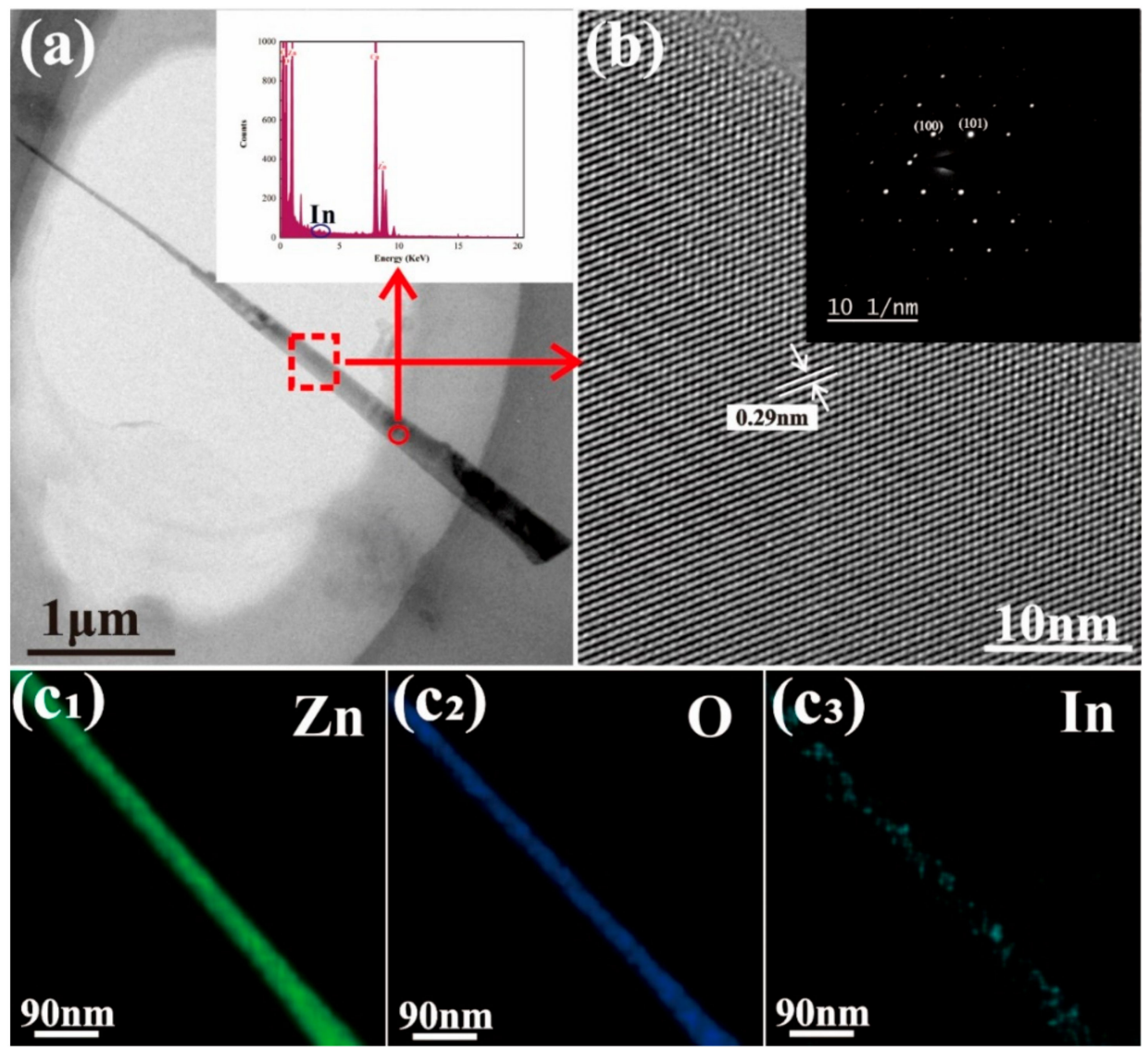

Figure 2. TEM characterization of a single In-doped $\mathrm{ZnO}$ nanowire. (a) Low-resolution TEM image; inset corresponding EDX spectrum. (b) High-resolution TEM image of the sample and selectedarea electron diffraction (SAED) pattern (inset). ( $\left.\mathbf{c}_{\mathbf{1}}-\mathbf{c}_{3}\right)$ EDX elemental mapping of $\left(\mathbf{c}_{1}\right) \mathrm{Zn},\left(\mathbf{c}_{2}\right) \mathrm{O}$, and $\left(c_{3}\right)$ In.

Figure $3 \mathrm{a}$ shows the XRD characterize of the In-doped $\mathrm{ZnO}$ nanowire with the $2 \theta$ range $25^{\circ}-60^{\circ}$, and from the result we can observe the peaks of $\mathrm{ZnO}$ (100), (002), and (101). Besides the peaks of $\mathrm{ZnO}$, the peaks for In and $\mathrm{Zn}$ are also clearly presented, which originate from the residual In and $\mathrm{Zn}$ after nanowire growth in the thin film underneath the nanowires. The XPS spectrum of the prepared sample is shown in Figure $3 b$ and the binding energy with a range of 0-1200 eV. As shown in XPS spectrum, the Zn $2 \mathrm{p}_{3 / 2}$ and $\mathrm{Zn}$ $2 \mathrm{p}_{1 / 2}$ peaks located at $\sim 1017.4$ and $\sim 1040.39 \mathrm{eV}$ are observed with the energy difference of $22.99 \mathrm{eV}$. In addition, the inset of Figure $3 \mathrm{~b}$ shows the enlarged peaks for In $3 \mathrm{~d}_{3 / 2}$ and In $3 \mathrm{~d}_{5 / 2}$ which located at 445.3 and $452.5 \mathrm{eV}$ and the energy difference is $6.8 \mathrm{eV}$. Closer inspection of the In-doped $\mathrm{ZnO}$ nanowires shows that, compared with the standard values of In $(7.5 \mathrm{eV})$ and $\mathrm{Zn}(22.97 \mathrm{eV})[39,40]$, the In $3 \mathrm{~d}$ peaks exhibit a positive shift which is probably caused by electron transfer from $\mathrm{ZnO}$ to In due to the strong electronic interaction between In and oxide support, which agrees with early report [24]. Meanwhile, the Zn 2p 
peaks exhibit a negative shift due to the electronegativity difference between $\mathrm{Zn}$ and In [24]. The O1s spectrum at $530.3 \mathrm{eV}$ is also observed in the XPS scan. From the XPS results, the In content can be calculated and the value is about $15 \%$. The result is much higher than that obtained from the in-situ EDX analysis in TEM. We think the high In content obtained from XPS originates from the thin film under the nanowires. After growth, the In-Zn film was partially oxidized and there are residual $\mathrm{In}$ and $\mathrm{Zn}$ in the $\mathrm{ZnO}$ thin film, which is confirmed by the XRD result. In the XPS measurement, the signal from the residual In element in the $\mathrm{ZnO}$ film will mix with the signal from the nanowires. Thus, a high In concentration was obtained in the XPS results. Therefore, the result from TEM analysis is more reflecting the true composition of the nanowire.
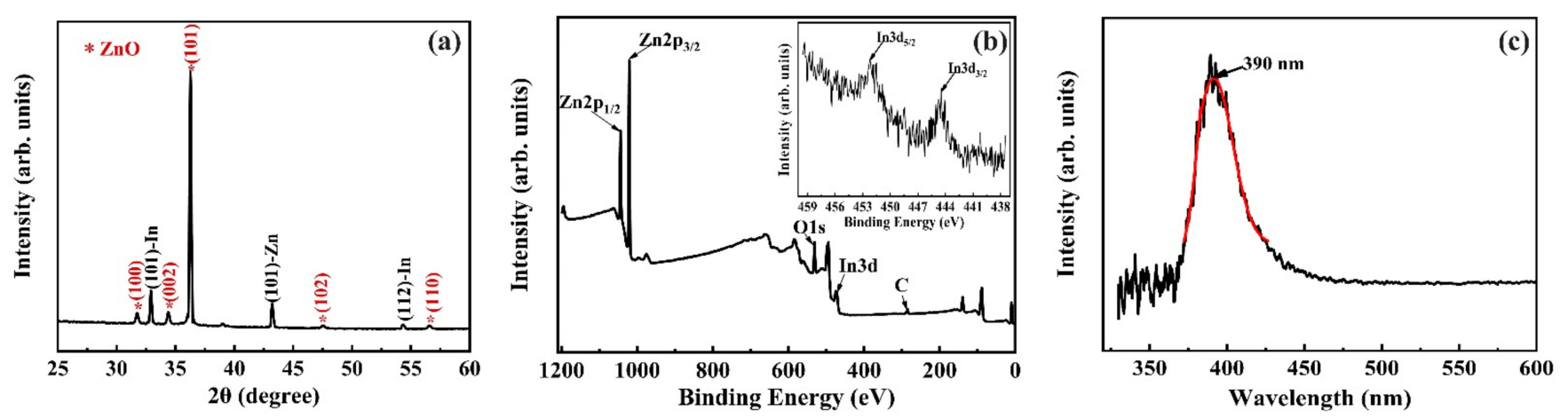

Figure 3. Characterization of ZnO nanowires with indium doping. (a) XRD pattern, (b) XPS spectrum, inset detail of XPS for In 3d enlarged peaks, (c) room-temperature PL spectrum of a single In-doped ZnO nanowire.

Figure 3c shows the normalized PL spectra of a single $\mathrm{ZnO}$ nanowire with indium doping, where the one observed UV emission peak around $390 \mathrm{~nm}$ corresponds to the intrinsic band edge emission. This band edge emission peak of the $\mathrm{ZnO}$ nanowire with indium doping is slightly blue-shifted compared with the previous results of an without element doping $\mathrm{ZnO}$ nanowire (UV band peak at $394 \mathrm{~nm}$ ) [27]. That is attributed to the shift of optic band gap owing to indium dopants contribute an increased number of electrons [24]. In addition, some early studies have reported two emission bands typically observed in the PL spectrum of $\mathrm{ZnO}$ nanowires, where the additional peak around $550 \mathrm{~nm}$ is owing to the existence of oxygen vacancies $[19,27]$. However, in this study this additional peak at the visible range was not observed, which implies a good crystal quality of the In-doped $\mathrm{ZnO}$ nanowires consistent with the TEM observations. In addition, the previously-reported without element doping $\mathrm{ZnO}$ nanowires grown by the thermal oxidation method exhibited strong green ( $\sim 550 \mathrm{~nm}$ wavelength) PL peak corresponding to the oxygen vacancies $[16,19]$. The difference in the PL results of the two types of thermal oxidation-grown $\mathrm{ZnO}$ nanowires may indicate that different growth mechanisms may function in the with element doping and without element doping $\mathrm{ZnO}$ nanowires.

\subsection{Growth Mechanism}

Previous work has represented the growth mechanism of $\mathrm{ZnO}$ nanowires without element doping from a $\mathrm{Zn}$ film by thermal oxidation using a strain-induced mass diffusion model [7]. According to the model, the supply of $\mathrm{Zn}$ atoms from the $\mathrm{Zn}$ film promote the $\mathrm{ZnO}$ continuous growth. Therefore, a cavity structure within the $\mathrm{ZnO}$ film under the growing $\mathrm{ZnO}$ nanowires is observed after growth. After In-doped $\mathrm{ZnO}$ nanowire growth, however, the film morphology exhibits a dense layer, indicating that a different mechanism may exist. To investigate the growth mechanism of In-doped $\mathrm{ZnO}$ nanowires, we characterized the cross-sectional morphology of nanowires prepared on $\mathrm{Si}$ after various growth times. Figure $4 \mathrm{a}-\mathrm{d}$ show the SEM images of In-Zn film surface morphology on Si substrates at the thermal oxidation times of $0\left(20^{\circ} \mathrm{C}\right), 90\left(250^{\circ} \mathrm{C}\right), 180\left(470{ }^{\circ} \mathrm{C}\right)$, and 270 $\left(470{ }^{\circ} \mathrm{C}\right) \mathrm{min}$, respectively, while Figure $4 \mathrm{a}_{1}-\mathrm{d}_{1}$ respectively show corresponding cross- 
sectional SEM images (where the inset of Figure $4 c_{1}$ is a magnified image). The trend of film thickness with heating time is plotted in Figure 4e.

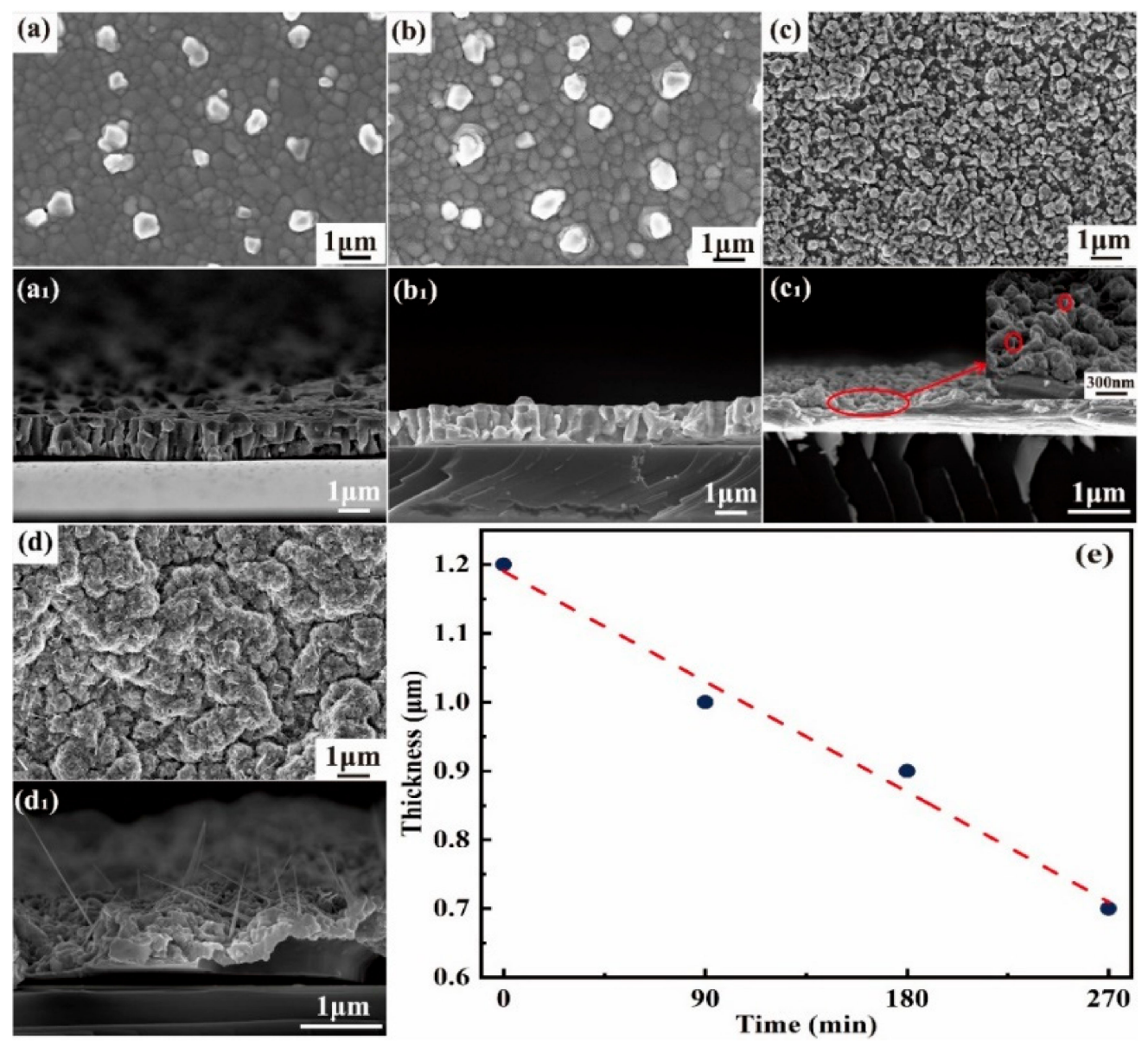

Figure 4. Top-view and cross-sectional SEM images of thin films and nanowires after a growth time of $\left(\mathbf{a}, \mathbf{a}_{\mathbf{1}}\right) 0 \mathrm{~min}\left(20^{\circ} \mathrm{C}\right),\left(\mathbf{b}, \mathbf{b}_{\mathbf{1}}\right) 90 \mathrm{~min}\left(250{ }^{\circ} \mathrm{C}\right),\left(\mathbf{c}, \mathbf{c}_{\mathbf{1}}\right) 180 \mathrm{~min}\left(470{ }^{\circ} \mathrm{C}\right)$, and $\left(\mathbf{d}, \mathbf{d}_{\mathbf{1}}\right) 270 \mathrm{~min}\left(470{ }^{\circ} \mathrm{C}\right) ;(\mathbf{e})$ $\mathrm{Zn}$ film thickness vs. heated time.

As can be seen from Figure 4a, the prepared alloy film is a continuous film, and the cross-sectional SEM image shows a discrete columnar structure $1.2 \mu \mathrm{m}$ in thickness. After heating for $90 \mathrm{~min}$, the film is melted and some small protrusions are visible on the surface of the film, which thins to $1 \mu \mathrm{m}$ thickness (Figure $4 \mathrm{~b}, \mathrm{~b}_{1}$ ). With increased heating time to $180 \mathrm{~min}$ and a temperature reaching $470{ }^{\circ} \mathrm{C}$, significant film melting occurs, larger protrusions appear on the surface, and a dense film is formed (Figure $4 \mathrm{c}, \mathrm{c}_{1}$ ). At the same time, some short nanowires emerge (inset of Figure $4 c_{1}$ ) and the film thickness reaches $\sim 900 \mathrm{~nm}$ after $180 \mathrm{~min}$. Under the temperature at $470{ }^{\circ} \mathrm{C}$ for $90 \mathrm{~min}$, the film thins and the nanowires lengthen. In addition, the film exhibits a rugged surface (Figure $4 d, d_{1}$ ) and is about $700 \mathrm{~nm}$ in thickness.

Analyzing the phenomena revealed by these SEM images, a model was proposed to describe the growth process of the $\mathrm{ZnO}$ nanowires with indium doping, which is illustrated in Figure 5. Previous studies have shown that element doped $\mathrm{ZnO}$ nanowire could be synthesized by a vapor-liquid-solid (VLS) mechanism [23,24,29,31]. We follow a self-catalytic VLS growth mechanism to explain the growth of the In-doped $\mathrm{ZnO}$ nanowires herein. When the In-Zn alloy film was placed in the quartz tube furnace and the temperature rises (Figure 5a), the relatively low melting point of indium cause indium agglomerates to precipitate on the film surface, which can act as catalysts (Figure 5b). Further increasing the temperature causes the zinc vapor, catalyzed by the indium agglomerates, to react 
with oxygen atoms in the air (Figure 5c) to form $\mathrm{ZnO}$ nanowires (Figure $5 \mathrm{~d}$ ). At the growth temperature of $470{ }^{\circ} \mathrm{C}$, the vapor pressure of $\mathrm{Zn}$ is about $100 \mathrm{~Pa}$ [41]. Furthermore, during growth process, the zinc in the film is oxidized into zinc oxide, which is an exothermic process. The released heat will raise the local temperature, which might lead to an even higher $\mathrm{Zn}$ vapor pressure during the growth. Simultaneously, some indium atoms diffuse into the growing $\mathrm{ZnO}$ nanowires, thus forming $\mathrm{In}$-doped $\mathrm{ZnO}$ nanowires. With increased growth duration, the indium particles become smaller and eventually are depleted. Therefore, the nanowires exhibit a morphology that is narrow at the top and wide at the bottom (Figure 5e). In addition, the vaporization of zinc reduces the $\mathrm{Zn}$ film thickness (Figure 5c-e).

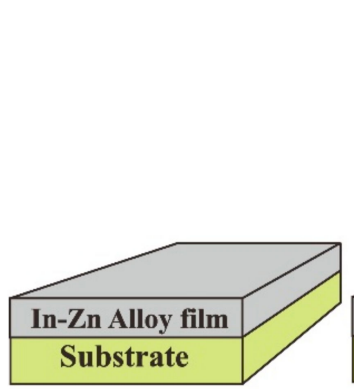

(a)

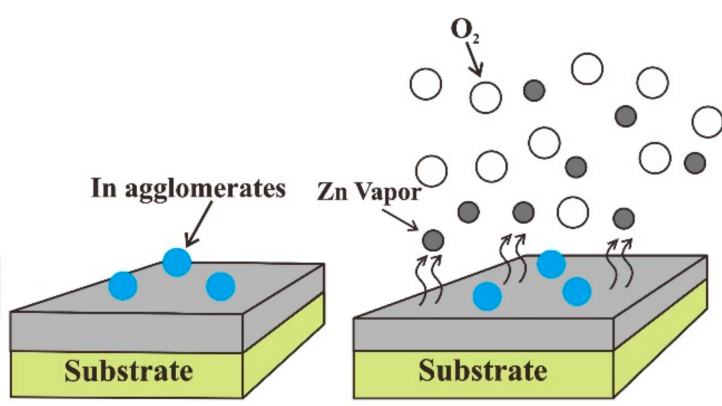

(b) (c)

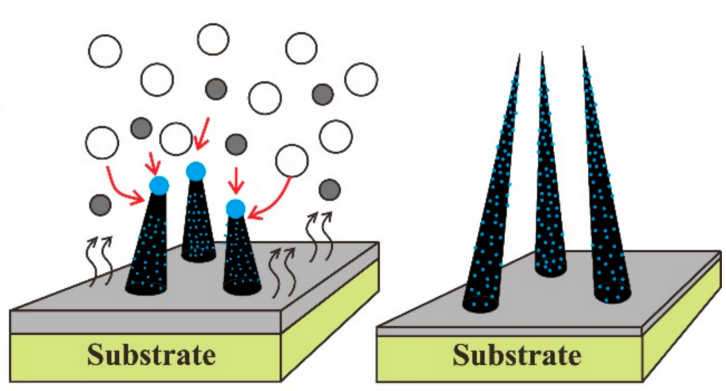

(d) (e)

Figure 5. Schematic diagram of the growth process of In-doped $\mathrm{ZnO}$ nanowires. (a) The In-Zn alloy film was deposited on the substrate, (b) indium agglomerates precipitated on the film surface, (c) zinc vaporized from the film, (d) ZnO nanowires grew from the In catalyst, (e) the In-doped $\mathrm{ZnO}$ nanowire after growth.

It is worthy to note the growth mechanism is different from that for the $\mathrm{ZnO}$ nanowire grown from pure $\mathrm{Zn}$ film using thermal oxidation method. In that case, the as-grown $\mathrm{ZnO}$ nanowires have a twin-crystalline structure with growth direction of 110 and high oxygen vacancies existed in the nanowire. While in this work, highly crystallized $\mathrm{ZnO}$ nanowires were obtained.

\subsection{Field Emission Properties}

The field emission properties of a $4.8 \times 4.8 \mathrm{~cm}^{2}$ In-doped $\mathrm{ZnO}$ nanowire array were studied. Figure 6 a shows the curve the field emission current density versus the applied electrical field (J-E) and the inset shows the corresponding Fowler-Nordheim (F-N) plot of the $\mathrm{ZnO}$ nanowires with indium doping. The results indicate a turn-on field of the prepared sample (corresponding to current density of $10 \mu \mathrm{A} / \mathrm{cm}^{2}$ ) is about $7.1 \mathrm{MV} / \mathrm{m}$. The obtained maximum emission current reaches $20 \mathrm{~mA}$, corresponding to a current density of $863.5 \mu \mathrm{A} / \mathrm{cm}^{2}$ at the electric field density $10.16 \mathrm{~V} / \mu \mathrm{m}$. The F-N plot shows non-linearity over the whole electric field range and could be divided into two linear sections at low electric fields and high electric fields, respectively (inset of Figure 6a). This nonlinearity may be caused by the heating effect and space charge effect [42], however the curve is bent downward at high field, so the space charge effect dominates. The field enhancement factor $\beta$ is about 1560 was calculated with the F-N equation from the linear section of the F-N curve at low field finding [19]. In this calculation for $\beta$, the work function of $3.98 \mathrm{eV}$ was used for the In-doped $\mathrm{ZnO}$ nanowires, which was measured using UPS. 

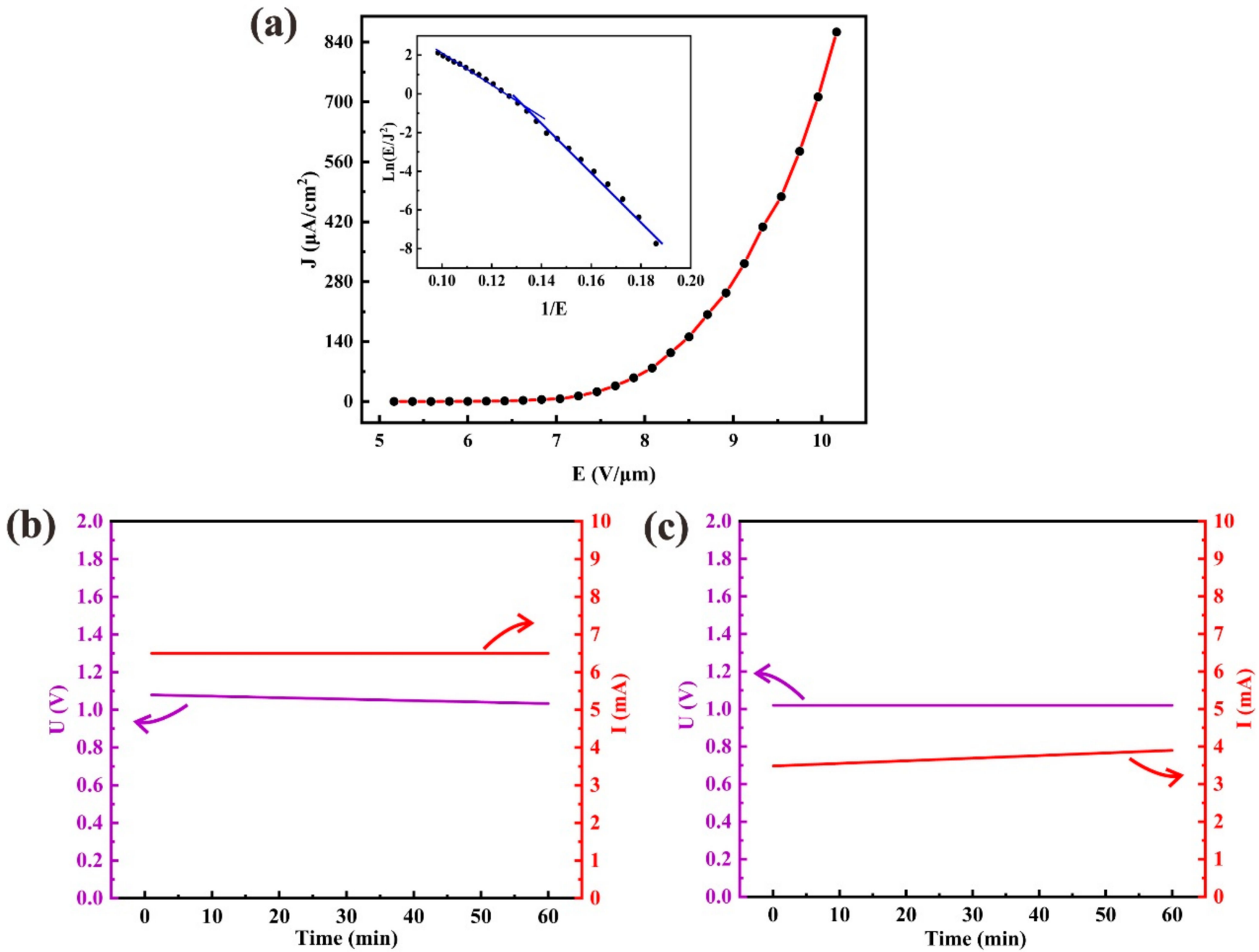

Figure 6. (a) Field emission curve (J-E) and Fowler-Nordheim (F-N) plot (inset) of ZnO nanowires with indium doping $(\mathbf{b}, \mathbf{c})$ Field emission stability of $(\mathbf{b})$ voltage $(\mathrm{U})$ with constant current at $6.5 \mathrm{~mA}$ and (c) direct current $(\mathrm{I})$ with constant voltage of $1.02 \mathrm{kV}$.

Figure $6 b, c$ show the field emission stability of current and voltage. The results obtained both under constant current mode and constant voltage mode were presented, which were obtained when the power supply operated in these two modes, respectively. Under constant current of $6.5 \mathrm{~mA}$ for $60 \mathrm{~min}$ the voltage value has a slight fluctuation from 1.08 to $1.03 \mathrm{kV}$; and at constant voltage of $1.0 \mathrm{kV}$ for $60 \mathrm{~min}$ the emission current increases from 3.48 to $3.9 \mathrm{~mA}$. The increase of emission current may be owing to the surface cleaning due to the heating effect induced by field emission current. To calculate the fluctuation of the emission current and applied voltage, we used [19]

$$
\begin{gathered}
\delta_{\text {current }}=\frac{\sum_{i=1}^{n}\left|I_{i}-I_{\text {average }}\right|}{n I_{\text {average }}} \times 100 \%, \\
\delta_{\text {voltage }}=\frac{\sum_{i=1}^{n}\left|V_{i}-V_{\text {average }}\right|}{n V_{\text {average }}} \times 100 \%,
\end{gathered}
$$

where $i$ is for the point of time, and at some point in time the value of current is $I_{i}$ and voltage is $V_{i}$; and $I_{\text {average }}$ is the average value of the current over the entire measurement period and $V_{\text {average }}$ is the same. The results show that the current fluctuation is $2.8 \%$ under a constant $1.0 \mathrm{kV}$ voltage and the voltage fluctuation is $1.1 \%$ under a constant $6.5 \mathrm{~mA}$ 
current. These results indicate these $\mathrm{ZnO}$ nanowires with indium doping has an excellent field emission stability.

Figure 7 shows a comparison in the emission current and corresponding current density of nanowires reported in this paper and that reported in previous literatures $[19,20,23,43-48]$. We note that the current increases with the increase of emission area (Figure 7a); however, because the emission area increase is disproportionately larger than the emission current increase of the samples, the current density decreases with increasing emission area (Figure $7 \mathrm{~b}$ ). For the samples possessing a similar area [19], the emission current of the element doped samples is greater than that of the samples without element doping. Compared with the previous reports and for large-area samples, higher value of the $\mathrm{ZnO}$ nanowires with indium doping in this work are obtained. These results provide an important guarantee for the subsequent fabrication of large-area devices.

(a)

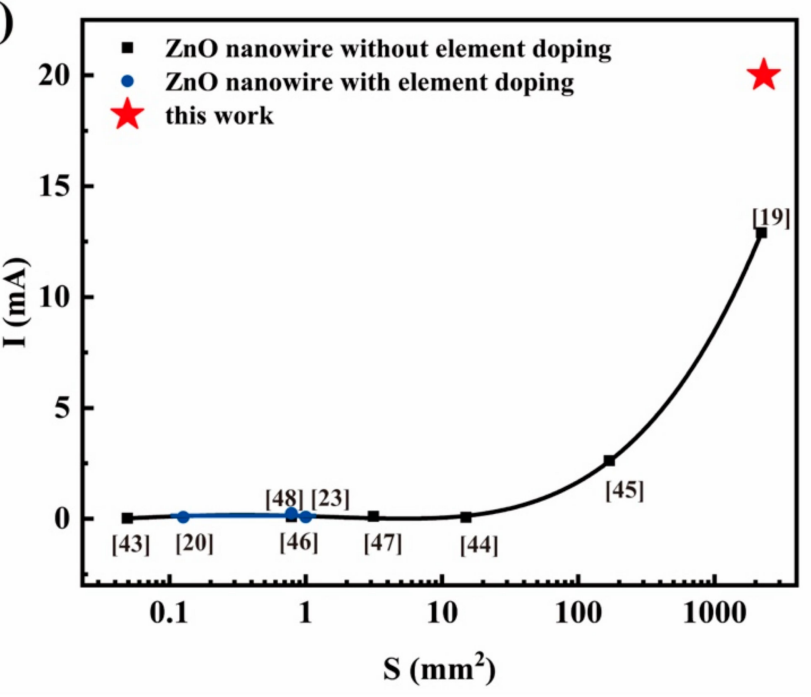

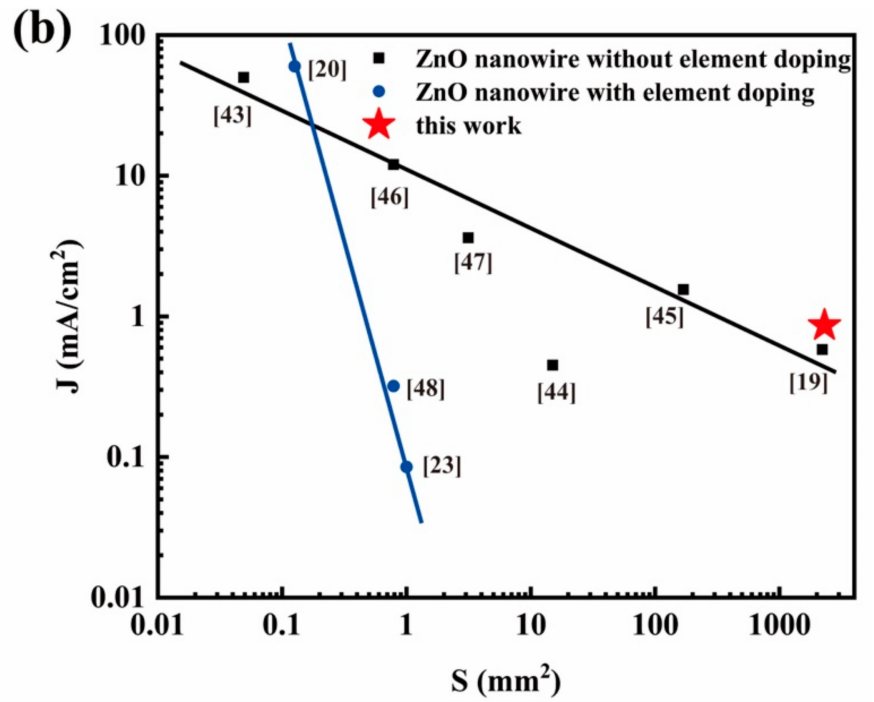

Figure 7. Comparison in the (a) emission current and (b) corresponding current density of nanowires reported in this paper and that reported in the literature (References given with data in square brackets).

\subsection{Electric Characteristics of Single Indium Doped $\mathrm{ZnO}$ Nanowire}

In order to explore the cause of high emission current from indium doped $\mathrm{ZnO}$ nanowires, the electrical characteristics of single indium doped $\mathrm{ZnO}$ nanowire were measured using a probe technique. Typical electrical characteristic of an individual $\mathrm{ZnO}$ nanowire with indium doping was presented in Figure 8, inset depicts the corresponding SEM image during the measurement. We calculated the corresponding geometrical parameters, resistance and conductivity of eight $\mathrm{ZnO}$ nanowires with indium doping and listed in Table 1 . The resistance of each In-doped $\mathrm{ZnO}$ nanowire was obtained by fitting each electrical I-V curve using the metal-nanowire-metal model reported in the literature [49]. The result shows that the conductivity of single $\mathrm{ZnO}$ nanowire with indium doping is in the order of $18-174 \mathrm{~S} / \mathrm{m}$. However, previous study showed the pure single crystal $\mathrm{ZnO}$ nanowires with wurtzite structure have lower conductivity about $10^{-2}-10^{-1} \mathrm{~S} / \mathrm{m}[26,50,51]$. The conductivity of the indium doped $\mathrm{ZnO}$ nanowire reported in this work is about $3 \sim 5$ orders of magnitude higher. 


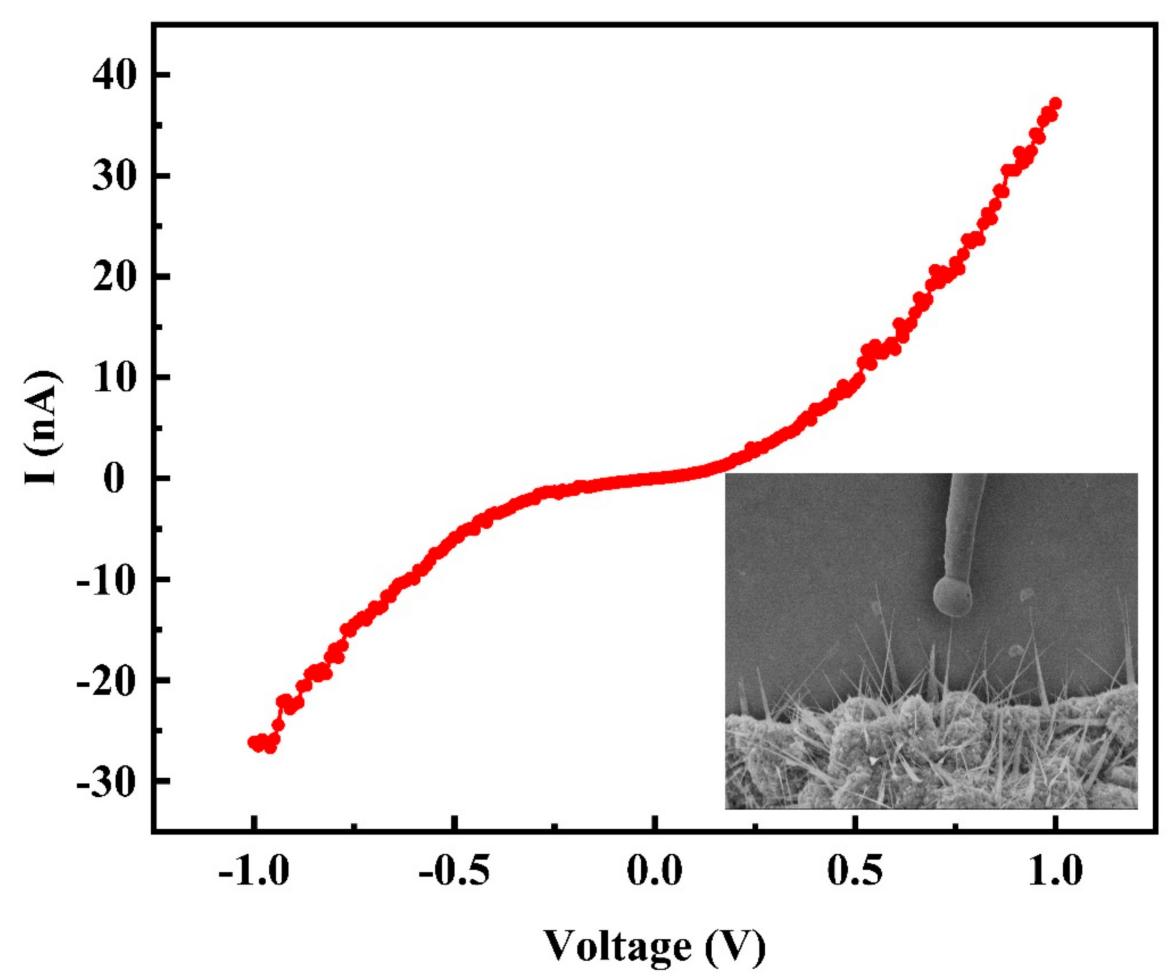

Figure 8. Typical electrical characteristics of an individual In-doped $\mathrm{ZnO}$ nanowire, inset is the SEM image during the measurement.

Table 1. Geometrical parameters, resistance and conductivity of single In-doped ZnO nanowire prepared using In-Zn film by thermal oxidation method.

\begin{tabular}{ccccc}
\hline Samples & $\begin{array}{c}\text { Length } \\
(\boldsymbol{\mu \mathbf { m } )}\end{array}$ & $\begin{array}{c}\text { Diameter } \\
(\mathbf{n m})\end{array}$ & $\begin{array}{c}\text { Resistance } \\
(\mathbf{M} \boldsymbol{)})\end{array}$ & $\begin{array}{c}\text { Conductivity } \\
\mathbf{( S / m )}\end{array}$ \\
\hline 1 & 3.8 & 80 & 35 & 22 \\
2 & 4.4 & 41 & 182 & 18 \\
3 & 5 & 40 & 56 & 71 \\
4 & 4.5 & 83 & 54 & 15 \\
5 & 5.1 & 65 & 8.8 & 174 \\
6 & 5.5 & 69 & 16.7 & 88 \\
7 & 7 & 57 & 65 & 42 \\
8 & 4.4 & 67 & 7.2 & 173 \\
\hline
\end{tabular}

In conclusion, we believe the higher conductivity contributes to the obtained high emission. Also, we think good nanowire crystallinity is a crucial factor for the higher emission current of the $\mathrm{ZnO}$ nanowire with indium doping. Recent studied shows that field emission from $\mathrm{ZnO}$ follows a field-induced hot-electron emission and nanowires remain stable when heated above $900 \mathrm{~K}$ when operated under high current [52]. The TEM and PL results demonstrated that the In-doped $\mathrm{ZnO}$ nanowires are single-crystal structures with few defects, leading to the improvement in thermal stability of In-doped $\mathrm{ZnO}$ nanowires. Therefore, the In-doped $\mathrm{ZnO}$ nanowires could endure high temperature induced by the high current.

\section{Application in Flat-Panel X-ray Source}

A $4.8 \times 4.8 \mathrm{~cm}^{2}$ flat-panel $X$-ray source was fabricated using the cathode discussed in Section 3.3. The X-ray source device comprised a diode structure whose schematic is shown in the inset of Figure 9a. A molybdenum thin film prepared on a quartz substrate was used as the anode, and the cathode and anode were separated by ceramic spacers with a height of $6 \mathrm{~mm}$. 

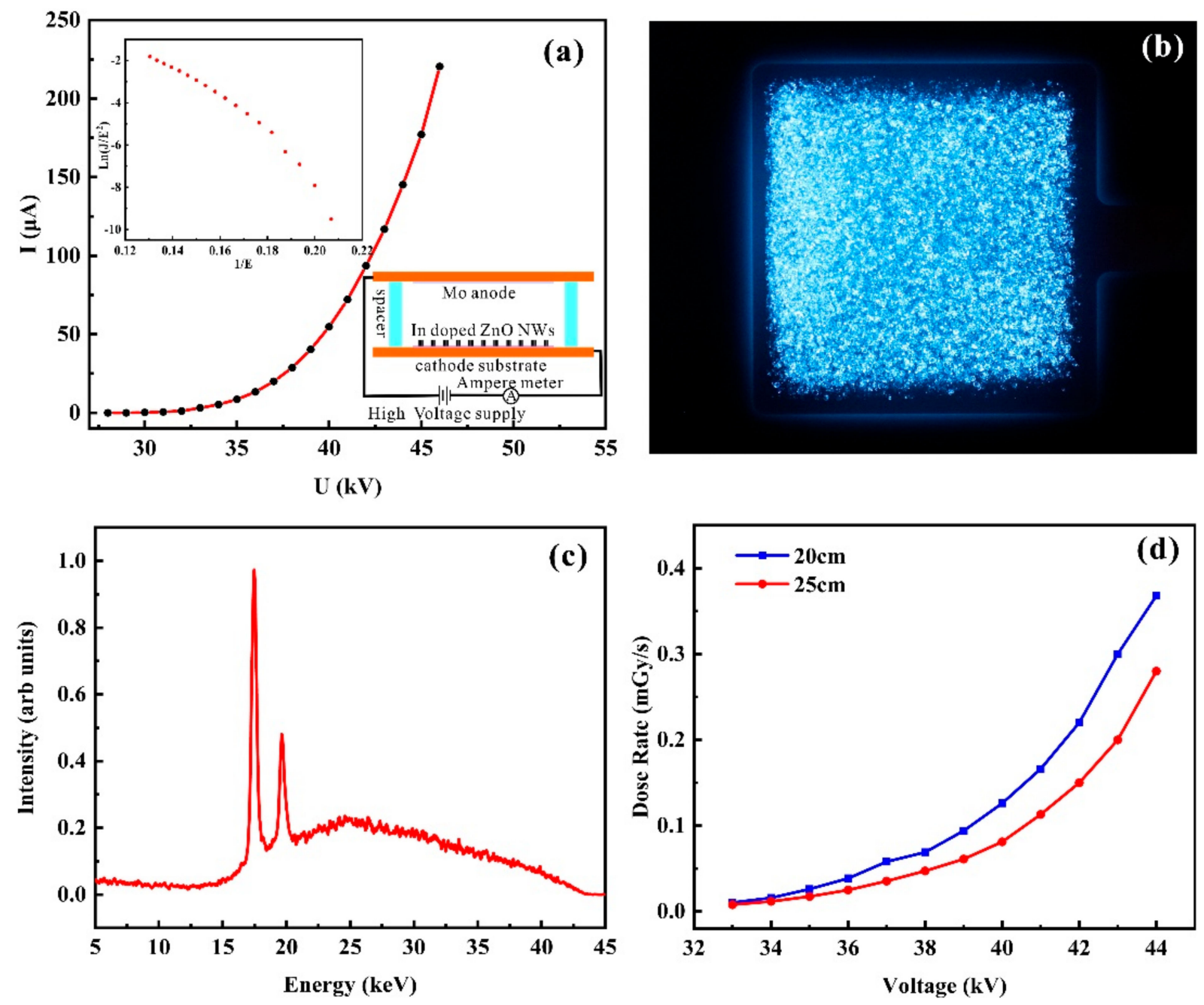

Figure 9. Characteristics of the flat-panel X-ray source. (a) I-V curve, (Upper Inset) F-N plot, and (Lower Inset) schematic diagram of testing device. (b) Visible light image recorded when the device is operated at a $46 \mathrm{kV}$ anode voltage. (c) Normalized X-ray energy spectra at a $46 \mathrm{kV}$ anode voltage. (d) X-ray dose rate vs. voltage for anode-cathode distance of $20 \mathrm{~cm}$ (blue squares) and $25 \mathrm{~cm}$ (red circles).

Figure 9a shows the I-V plot of the flat-panel X-ray source and the corresponding F-N plot, where the former demonstrates that the device has an emission current of $225 \mu \mathrm{A}$ under a $46 \mathrm{kV}$ anode voltage. The $\mathrm{X}$-ray characteristics of this device was subsequently measured under this voltage. Figure $9 \mathrm{~b}$ shows an image of the field emission under $46 \mathrm{kV}$ anode voltage, where the bluish bright contrast corresponding to the field emission was owing to electron bombardment of the molybdenum-coated quartz glass. Repeated testing of the device over a few days demonstrated the repeatability of the results at high voltage. To analyze the uniformity of the emission as represented in the image of Figure $9 b$, we calculated the average emission area rate and found it to be $95 \%$. We therefore conclude that the X-ray source exhibits a superior X-ray emission uniformity owing to the uniform emission of the In-doped $\mathrm{ZnO}$ nanowires.

Figure $9 \mathrm{c}$ shows the $\mathrm{X}$-ray energy spectra of the device, which exhibits two characteristic peaks of molybdenum located near 17.5 and $19.6 \mathrm{keV}$. We note that the low-energy $\mathrm{X}$-rays (i.e., $<15 \mathrm{keV}$ ) are attenuated by the quartz glass. Furthermore, the change of $\mathrm{X}$-ray dose rate with anode voltage was measured at the distances of 20 and $25 \mathrm{~cm}$ from the X-ray source, as shown in Figure 9d. At each distance, an increasing anode voltage resulted in an increased dose rate; while the dose rate decreased significantly with increasing the distance. 
A maximum radiation dose rate of $368 \mu \mathrm{Gy} / \mathrm{s}$ was measured at a $44 \mathrm{kV}$ anode voltage $20 \mathrm{~cm}$ from the front of the $X$-ray source.

The imaging characteristics of the $\mathrm{X}$-ray source were tested by tape the non-biological and biological objects to the surface of the $X$-ray imaging detector. Figure 10a show the $X$-ray image of a microprocessor chip using the dental imaging detector placed $35 \mathrm{~cm}$ from the X-ray source, in which the X-ray image clearly shows the thin metal wire structure inside the chip. Figure 10b show the X-ray image of a calculator taken by the flat panel detector, with a $75 \mathrm{~cm}$ distance between the detector and the device. The internal structure of the calculator can be clearly resolved and the number of spring coils can be accurately counted. Meanwhile, biological images were also presented. Figure 10c show the imaging result of a hippocampal specimen which can clearly distinguish the skeleton joints and the head structure. Figure 10d show the imaging result of a fresh loach. From the image we can clearly distinguish its skeletal structure and the distribution of internal organs.
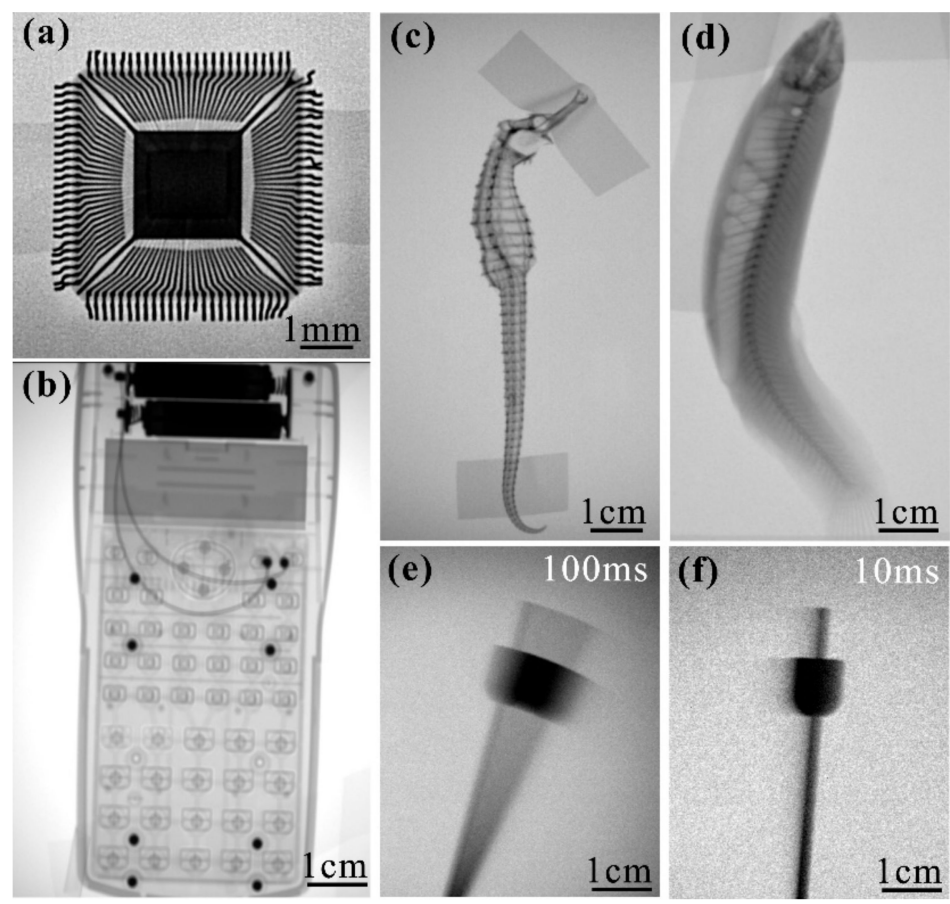

Figure 10. X-ray images of non-biological and biological samples (a-d). (a) An integrated circuit chip. (b) A calculator, (c) hippocampal specimen and (d) fresh loach. Images of moving metronome needle taken using the $\mathrm{X}$-ray source driven using pulsed high voltage with the pulse width of $100 \mathrm{~ms}$ (e) and $10 \mathrm{~ms}(\mathbf{f})$.

Furthermore, we image moving objects using the fabricated device when the device is driven by a pulsed high voltage supply. High voltage pulses of $46 \mathrm{kV}$ with the widths of $250,100,50,25$, and $10 \mathrm{~ms}$ were applied to the device, respectively. A metronome was used as the imaging object where placed $55 \mathrm{~cm}$ from the device and the frequency of the metronome is set to $1 \mathrm{~Hz}$. Figure 10e,f show the images of metronome needle obtained using pulse widths of 100 and $10 \mathrm{~ms}$, respectively. We founded the continuous shadows appear on the image when the pulse width is $100 \mathrm{~ms}$. When the pulse width is $10 \mathrm{~ms}$, almost stationary image of the metronome needle could be captured. The results show that the fabricated device using $\mathrm{ZnO}$ nanowire with indium doping as cathode has potential application prospect in dynamic imaging.

\section{Conclusions}

$\mathrm{ZnO}$ nanowire arrays with indium doping were prepared by the thermal oxidation technique, where the In was successfully doped into the nanowires at a content of approx- 
imately 1 at $\%$. A high field emission current of $20 \mathrm{~mA}$ was acquired from the large-area (i.e., $4.8 \times 4.8 \mathrm{~cm}^{2}$ ) In-doped $\mathrm{ZnO}$ nanowire FEAs owing to the good crystal quality of the In-doped $\mathrm{ZnO}$ nanowires. Excellent emission stability was also achieved under constant current and constant voltage. A large-area flat-panel X-ray source was fabricated using the $\mathrm{ZnO}$ nanowire array with indium doping as the cathode, where a radiation dose rate of $368 \mu \mathrm{Gy} / \mathrm{s}$ was achieved. In addition, clear X-ray imaging was achieved both for static and moving objects. This work indicates that In-doped $\mathrm{ZnO}$ nanowires prepared by the thermal oxidation method are promising for applications in large-area vacuum microelectronics devices.

Author Contributions: J.C., S.D. and J.S. conceived and designed the experiments. Y.Z., Y.C., G.Z., and R.Z. performed all experiments. Y.Z., J.C., and S.D. wrote the paper. All authors discussed and analyzed the results. All authors have read and agreed to the published version of the manuscript.

Funding: This work was supported by the National Key Research and Development Program of China (Grant No. 2016YFA0202001), the National Natural Science Foundation of China (Grant No. 91833303 \& 61701551), the Fundamental Research Funds for the Central Universities, the Science and Technology Department of Guangdong Province, and the Guangzhou Science Technology and Innovation Commission.

Data Availability Statement: Data is contained within the article.

Conflicts of Interest: The authors declare no conflict of interest.

\section{References}

1. Youh, M.J.; Tseng, C.L.; Jhuang, M.H.; Chiu, S.C.; Huang, L.H.; Gong, J.A.; Li, Y.Y. Flat Panel Light Source with Lateral Gate Structure Based on SiC Nanowire Field Emitters. Sci. Rep. 2015, 5, 10976. [CrossRef] [PubMed]

2. Chen, D.K.; Song, X.M.; Zhang, Z.P.; Li, Z.P.; She, J.C.; Deng, S.Z.; Xu, N.S.; Chen, J. Transmission Type Flat-Panel X-ray Source Using ZnO Nanowire Field Emitters. Appl. Phys. Lett. 2015, 107, 243105. [CrossRef]

3. Li, L.; Zhang, Y.; Fang, X.; Zhai, T.; Liao, M.; Sun, X.; Koide, Y.; Bando, Y.; Golberg, D. WO 3 Nanowires on Carbon Papers: Electronic Transport, Improved Ultraviolet-Light Photodetectors and Excellent Field Emitters. J. Mater. Chem. 2011, 21, 6525-6530. [CrossRef]

4. Zhang, Z.P.; Wang, K.; Zheng, K.S.; Deng, S.Z.; Xu, N.S.; Chen, J. Electron Bombardment Induced Photoconductivity and High Gain in a Flat Panel Photodetector Based on a ZnS Photoconductor and ZnO Nanowire Field Emitters. ACS Photonics 2018, 5, 4147-4155. [CrossRef]

5. Lee, C.J.; Lee, T.J.; Lyu, S.C.; Zhang, Y.; Ruh, H.; Lee, H.J. Field Emission from Well-Aligned Zinc Oxide Nanowires Grown at Low Temperature. Appl. Phys. Lett. 2002, 81, 3648-3650. [CrossRef]

6. Zhao, C.X.; Li, Y.F.; Zhou, J.; Li, L.Y.; Deng, S.Z.; Xu, N.S.; Chen, J. Large-Scale Synthesis of Bicrystalline ZnO Nanowire Arrays by Thermal Oxidation of Zinc Film: Growth Mechanism and High-Performance Field Emission. Cryst. Growth Des. 2013, 13, 2897-2905. [CrossRef]

7. Zhang, Z.P.; Song, X.M.; Chen, Y.C.; She, J.C.; Deng, S.Z.; Xu, N.S.; Chen, J. Controllable Preparation of 1-D and Dendritic ZnO Nanowires and Their Large Area Field-Emission Properties. J. Alloys Compd. 2017, 690, 304-314. [CrossRef]

8. Liu, Y.F.; Li, C.; Wang, J.S.; Fan, X.Y.; Yuan, G.; Xu, S.F.; Xu, M.F.C.; Zhang, J.; Zhao, Y.J. Field Emission Properties of ZnO Nanorod Arrays by Few Seed Layers Assisted Growth. Appl. Surf. Sci. 2015, 331, 497-503. [CrossRef]

9. Hollinger, R.; Gupta, D.; Zapf, M.; Röder, R.; Kartashov, D.; Ronning, C.; Spielmann, C. Single Nanowire Defined Emission Properties of ZnO Nanowire Arrays. J. Phys. D Appl. Phys. 2019, 52, 295101. [CrossRef]

10. Alfaify, S.J.N.; Letters, N. Enhanced Field Emission Properties of Aligned ZnO Nanowires. Nanosci. Nanotech. Lett. 2016, 8, 521-526.

11. Wan, Q.; Yu, K.; Wang, T.H.; Lin, C.L. Low-Field Electron Emission from Tetrapod-Like ZnO Nanostructures Synthesized by Rapid Evaporation. Appl. Phys. Lett. 2003, 83, 2253-2255. [CrossRef]

12. Bueno, C.; Pacio, A.; Osorio, E.; Alvarado, J.A.; Maestre, D.; Cremades, A.; García, J.A.; Flores-Carrasco, G.; Juárez, H. Growth Mechanism and Optical Properties of Nano and Microstructures of ZnO Obtained by Thermal Oxidation of Zinc Powders at Atmospheric Pressure. Solid State Phenom. 2019, 286, 33-39. [CrossRef]

13. Escobedo-Morales, A.; Aranda-García, R.; Chigo-Anota, E.; Pérez-Centeno, A.; Méndez-Blas, A.; Arana-Toro, C. ZnO Micro- and Nanostructures Obtained by Thermal Oxidation: Microstructure, Morphogenesis, Optic. Pht. Sci. Cryst. 2016, 6, 135. [CrossRef]

14. Chen, D.K.; Xu, Y.; Zhang, G.F.; Zhang, Z.P.; She, J.C.; Deng, S.Z.; Xu, N.S.; Chen, J. A Double-Sided Radiating Flat-Panel X-ray Source Using ZnO Nanowire Field Emitters. Vacuum 2017, 144, 266-271. [CrossRef]

15. Zhang, Z.P.; Wang, K.; Zheng, K.S.; Deng, S.Z.; Xu, N.S.; Chen, J. A Flat Panel Photodetector Formed by a ZnS Photoconductor and ZnO Nanowire Field Emitters Achieving High Responsivity from Ultraviolet to Visible Light for Indirect-Conversion X-ray Imaging. J. Lightwave Tech. 2018, 36, 5010-5015. [CrossRef] 
16. Li, Y.F.; Zhang, Z.P.; Zhang, G.F.; Zhao, L.; Deng, S.Z.; Xu, N.S.; Chen, J. Optimizing the Field Emission Properties of ZnO Nanowire Arrays by Precisely Tuning the Population Density and Application in Large-Area Gated Field Emitter Arrays. ACS Appl. Mater. Interfaces 2017, 9, 3911-3921. [CrossRef]

17. Vempati, S.; Shetty, A.; Dawson, P.; Nanda, K.; Krupanidhi, S.B. Cobalt-Doped ZnO Nanowires on Quartz: Synthesis by Simple Chemical Method and Characterization. J. Cryst. Growth 2012, 343, 7-12. [CrossRef]

18. Kennedy, J.; Fang, F.; Futter, J.; Leveneur, J.; Murmu, P.P.; Panin, G.N.; Kang, T.W.; Manikandan, E. Synthesis and Enhanced Field Emission of Zinc Oxide Incorporated Carbon Nanotubes. Diamo. Related Mater. 2017, 71, 79-84. [CrossRef]

19. Wang, L.B.; Zhao, Y.Y.; Zheng, K.S.; She, J.C.; Deng, S.Z.; Xu, N.S.; Chen, J. Fabrication of Large-Area ZnO Nanowire Field Emitter Arrays by Thermal Oxidation for High-Current Application. Appl. Surf. Sci. 2019, 484, 966-974. [CrossRef]

20. Liang, Y. Ge-Doped ZnO Nanowire Arrays as Cold Field Emitters with Excellent Performance. Nanotechnology 2019, $30,375603$. [CrossRef]

21. Lv, Y.Y.; Zhang, Z.Y.; Yan, J.F.; Zhao, W.; Zhai, C.X. Al Doping Influences on Fabricating ZnO Nanowire Arrays: Enhanced Field Emission Property. Ceram. Int. 2018, 44, 7454-7460. [CrossRef]

22. Young, S.J.; Yang, C.C.; Lai, L.T. Review-Growth of Al-, Ga-, and In-Doped ZnO Nanostructures via a Low-Temperature Process and Their Application to Field Emission Devices and Ultraviolet Photosensors. J. Electrochem. Soc. 2016, 164, B3013-B3028. [CrossRef]

23. Chang, L.W.; Yeh, J.W.; Cheng, C.L.; Shieu, F.S.; Shih, H.C. Field Emission and Optical Properties of Ga-Doped ZnO Nanowires Synthesized via Thermal Evaporation. Appl. Surf. Sci. 2011, 257, 3145-3151. [CrossRef]

24. Ahmad, M.; Sun, H.; Zhu, J. Enhanced Photoluminescence and Field-Emission Behavior of Vertically Well Aligned Arrays of In-Doped ZnO Nanowires. ACS Appl. Mater. Interfaces 2011, 3, 1299-1305. [CrossRef] [PubMed]

25. Huang, Y.H.; Zhang, Y.; Gu, Y.S.; Bai, X.D.; Qi, J.J.; Liao, Q.L.; Liu, J. Field Emission of a Single In-Doped ZnO Nanowire. J. Phys. Chem. C 2007, 111, 9039-9043. [CrossRef]

26. Yuan, G.D.; Zhang, W.J.; Jie, J.S.; Fan, X.; Tang, J.X.; Shafiq, I.; Ye, Z.Z.; Lee, C.S.; Lee, S.T. Tunable n-Type Conductivity and Transport Properties of Ga-doped ZnO Nanowire Arrays. Adv. Mater. 2008, 20, 168-173. [CrossRef]

27. Chen, Y.W.; Liu, Y.C.; Lu, S.X.; Xu, C.S.; Shao, C.L.; Wang, C.; Zhang, J.Y.; Lu, Y.M.; Shen, D.Z.; Fan, X.W. Optical Properties of $\mathrm{ZnO}$ and ZnO:In Nanorods Assembled by Sol-Gel Method. J. Phys. Chem. 2005, 123, 134701. [CrossRef]

28. Wang, J.L.; Hsieh, T.Y.; Yang, P.Y.; Hwang, C.C.; Shye, D.C.; Lee, I.C. Oxygen Annealing Effect on Field-Emission Characteristics of Hydrothermally Synthesized Al-Doped ZnO Nanowires. Surf. Coat. Technol. 2013, 231, 423-427. [CrossRef]

29. Jia, X.; Xu, H.; Gao, J. Ultralow Electron Mobility of An Individual Cu-Doped ZnO Nanowire. Phys. Status Solidi 2013, 210, 1217-1220. [CrossRef]

30. Xu, C.; Kim, M.; Chun, J.; Kim, D. Growth of Ga-Doped ZnO Nanowires by Two-Step Vapor Phase Method. Appl. Phys. Lett. 2005, 86, 133107. [CrossRef]

31. Ahmad, M.; Pan, C.; Zhu, J. Electrochemical Determination of L-Cysteine by an Elbow Shaped, Sb-Doped ZnO NanowireModified Electrode. J. Mater. Chem. 2010, 20, 7169-7174. [CrossRef]

32. Nunes, P.; Fortunato, E.; Tonello, P.; Fernandes, F.B.; Vilarinho, P.; Martins, R. Effect of Different Dopant Elements on The Properties of ZnO Thin Films. Vacuum 2001, 64, 281-285. [CrossRef]

33. Wang, Y.; Chen, Y.C.; Song, X.M.; Zhang, Z.P.; She, J.C.; Deng, S.Z.; Xu, N.S.; Chen, J. Electrical Properties of Fluorine-doped ZnO Nanowires Formed by Biased Plasma Treatment. Phys. E 2018, 99, 254-260. [CrossRef]

34. Liu, Y.M.; Zhao, L.; Zhang, Z.P.; Chen, D.K.; Zhang, G.F.; She, J.C.; Deng, S.Z.; Xu, N.S.; Chen, J. Fabrication of ZnO Nanowire Field-Emitter Arrays with Focusing Capability. IEEE Trans. Electron Dev. 2018, 65, 1982-1987. [CrossRef]

35. Zhao, L.; Chen, Y.C.; Zhang, Z.P.; Cao, X.Q.; Zhang, G.F.; She, J.C.; Deng, S.Z.; Xu, N.S.; Chen, J. Coplanar-Gate ZnO Nanowire Field Emitter Arrays with Enhanced Gate-Control Performance Using a Ring-Shaped Cathode. Sci. Rep. 2018, 8, 12294. [CrossRef]

36. Cao, X.Q.; Yin, J.; Wang, L.B.; Zhang, G.F.; Deng, S.Z.; She, J.C.; Xu, N.S.; Chen, J. Fabrication of Coaxis-Gated ZnO Nanowire Field-Emitter Arrays with In-Plane Focusing Gate Electrode Structure. IEEE Trans. Electron Dev. 2020, 67, 677-683. [CrossRef]

37. Zhao, L.; Chen, Y.X.; Liu, Y.M.; Zhang, G.F.; She, J.C.; Deng, S.Z.; Xu, N.S.; Chen, J. Integration of ZnO Nanowires in Gated Field Emitter Arrays for Large-Area Vacuum Microelectronics Applications. Curr. Appl. Phys. 2017, 17, 85-91. [CrossRef]

38. Chen, Y.C.; Song, X.M.; Li, Z.B.; She, J.C.; Deng, S.Z.; Xu, N.S.; Chen, J. Penetration Length-dependent Hot Electrons in The Field Emission from ZnO Nanowires. Appl. Surf. Sci. 2018, 427, 573-580. [CrossRef]

39. Muilenbenger, G.E. (Ed.) Handbook of X-ray Photoelectron Spectroscopy; Perkin-Elmer Corporation: Eden Prarie, MN, USA, 1979.

40. Lide, D.R. (Ed.) Chemical Rubber Company Handbook of Chemistry and Physics, 81th ed.; CRC Press: Boca Raton, FL, USA, 2000.

41. Klimova, A.M.; Ananichev, V.A.; Arif, M.; Blinov, L.N. Investigation of the Saturated Vapor Pressure of Zinc, Selenium, and Zinc Selenide. Glass Phys. Chem. 2005, 31, 760-762. [CrossRef]

42. Barbour, J.P.; Dolan, W.W.; Trolan, J.K.; Martin, E.E.; Dyke, W.P.J.P.R. Space-Charge Effects in Field Emission. Phys. Rev. 1953, 92, 45-51. [CrossRef]

43. Semet, V.; Binh, V.T.; Pauporté, T.; Joulaud, L.; Vermersch, F. Field Emission Behavior of Vertically Aligned ZnO Nanowire Planar Cathodes. J. Appl. Phys. 2011, 109, 054301. [CrossRef]

44. Yang, Z.C.; Zhao, Q.; Ou, Y.X.; Wang, W.; Li, H.; Yu, D. Enhanced Field Emission from Large Scale Uniform Monolayer Graphene Supported by Well-Aligned ZnO Nanowire Arrays. Appl. Phys. Lett. 2012, 101, 173107. [CrossRef] 
45. Xu, H.J.; Chan, Y.F.; Su, L.; Li, D.Y.; Sun, X.M. Enhanced Field Emission from ZnO Nanowires Grown on a Silicon Nanoporous Pillar Array. J. Appl. Phys. 2010, 108, 114301. [CrossRef]

46. Lee, C.Y.; Li, Y.S.; Lin, P.; Tseng, T.Y. Field-Emission Triode of Low-Temperature Synthesized ZnO Nanowires. IEEE Trans. Nanotech. 2006, 5, 216-219.

47. Liao, L.; Li, J.C.; Wang, D.F.; Liu, C.; Fu, Q. Electron Field Emission Studies on ZnO Nanowires. Mater. Lett. 2005, 59, $2465-2467$. [CrossRef]

48. Chen, Z.H.; Tang, Y.B.; Liu, Y.; Yuan, G.D.; Zhang, W.F.; Zapien, J.A.; Lee, S.T. ZnO Nanowire Arrays Grown on Al:ZnO Buffer Layers and Their Enhanced Electron Field Emission. J. Appl. Phys. 2009, 106, 064303.1-064303.6. [CrossRef]

49. Zhang, Z.Y.; Yao, K.; Liu, Y.; Jin, C.H.; Liang, X.L.; Chen, Q.; Peng, L.M. Quantitative Analysis of Current-Voltage Characteristics of Semiconducting Nanowires: Decoupling of Contact Effects. Adv. Funct. Mater. 2010, 17, 2478-2489. [CrossRef]

50. Hsu, C.L.; Chang, S.J.; Lin, Y.R.; Li, P.C.; Lin, T.S.; Tsai, S.Y.; Lu, T.H.; Chen, I.C. Ultraviolet Photodetectors with Low Temperature Synthesized Vertical ZnO Nanowires. Chem. Phys. Lett. 2005, 416, 75-78. [CrossRef]

51. Zhou, M.J.; Zhu, H.J.; Jiao, Y.; Rao, Y.Y.; Hark, S.K.; Liu, Y.; Peng, L.M.; Li, Q. Optical and Electrical Properties of Ga-doped ZnO Nanowire Arrays on Conducting Substrates. J. Phys. Chem. C 2009, 113, 8945-8947. [CrossRef]

52. Chen, Y.C.; Luo, S.S.; Cao, X.Q.; Li, Y.F.; She, J.C.; Deng, S.Z.; Chen, J. Stable Heating Above $900 \mathrm{~K}$ in the Field Emission of ZnO Nanowires: Mechanism for Achieving High Current in Large Scale Field Emitter Arrays. Adv. Electron. Mater. 2020, 2000624. [CrossRef] 